\title{
Study on the chemical composition of teak wood extracts in different organic solvents
}

\author{
Dumitru Eugen Colbu ${ }^{(1)}$, \\ lon Sandu ${ }^{(2-3-4)}$, \\ Viorica Vasilache ${ }^{(2)}$, \\ Kamel Earar ${ }^{(5)}$, \\ Elena Daniela Paraschiv ${ }^{(6)}$, \\ Ioan Gabriel Sandu ${ }^{(7)}$, \\ Diana Bulgaru Iliescu ${ }^{(6)}$, \\ Andrei Victor Sandu ${ }^{(7-8)}$
}

\begin{abstract}
Teak wood (Tectona grandis Linn $F$.) is known for its high natural resistance to attack by microorganisms. For this reason, teak wood is used for restoration works. This paper provides an assessment of the extraction capacity of various organic solvents and the chemical and physical-structural characteristics of extracts of teak wood with an age of 40 years. On the basis of literature data, we selected the solvents with potential synergetic activity in preservation treatments. For this purpose we used the SEM-EDX and GC+MS methods, assisted by computerized processing software, and corroborated the data obtained from these two instrumental techniques.
\end{abstract}

Keywords: Teak Wood, Composition, Organic Solvents, Extracts, SEM-EDX, GC+MS

tangential, L-longitudinal - Sandu 2008). The specificity of the wood's resistance to the attack of fungi and xylophagous insects (anobides, termites, beetles, and marine borers) is contingent on this anisotropy. Also, the presence of an extractable organic compound rises the resistance against fungi (Vasilache et al. 2009, Hayashi et al. 2010).

It is known that wooden species with high natural durability have a wide range of uses and a much greater added value on the market. Among them, teak wood (Tectona grandis Linn F.) is renowned for its high resistance to the attack of many microorganisms (Kirker et al. 2013, Tascioglu et al. 2013, Brocco et al. 2017).

Once it is processed into an object, wood generally deteriorates and/or degrades under the influence of climatic factors and of tor), which through unauthorized preserva-
(1) Faculty of Geography and Geology, Doctoral School of Geosciences, Alexandru loan Cuza University of lasi, 20A Carol I St., Corp B, 700506 lasi (Romania); (2) Institute of Interdisciplinary Research, ARHEOINVEST Center, Alexandru loan Cuza University of lasi, 11 Carol I St., 700506 lasi (Romania); (3) Romanian Inventors Forum, 3 Sf. Petru Movila St., 700089 lasi (Romania); (4) Academy of Romanian Scientists (AOSR), 54 Splaiul Independentei St., Sect. 5, 050094 Bucharest (Romania); (5) Faculty of Medicine and Pharmacy, "Dunarea de Jos" University of Galati, 35 Al.I. Cuza St., 800216 Galati (Romania); (6) “Grigore T. Popa” University of Medicine and Pharmacy of lasi, Institute of Forensic Medicine lasi, 4 Buna Vestire St., 700455 lasi (Romania); (7) Faculty of Material Science and Engineering, Gheorghe Asachi Technical University of lasi, 41 D. Mangeron St., 700050 lasi (Romania); (8) National Institute for Research and Development for Environmental Protection INCDPM, 294 Splaiul Independentei, 060031 Bucharest (Romania)

@ Andrei Victor Sandu (sav@tuiasi.ro)

Received: Dec 09, 2020 - Accepted: May 06, 2021

Citation: Colbu DE, Sandu I, Vasilache V, Earar K, Paraschiv ED, Sandu IG, Bulgaru Iliescu D, Sandu AV (2021). Study on the chemical composition of teak wood extracts in different organic solvents. iForest 14: 329-336. - doi: 10.3832/ifor3717-014 [online 2021-07-09]

Communicated by: Luigi Todaro chemical (pollution), microbiological (fungi, xylophagous insects, rodents, etc.) and radiative agents (fire and very-high temperatures, UV and gamma radiation). The two effects are the result of processes that use different mechanisms (physical-structural destruction or chemical alteration), which are regulated by the presence of one or several components with insecto-fungal, hydrophobic or fire-retardant activity that originate from the native wood (natural product) or from the use of dispersed systems for mitigating or stopping the deterioration and/or degradation by means of preservation operations (lurcovschi et al. 2017, Sandu 2008, Spiridon et al. 2017).

Concerning heritage goods, we cannot overlook human impact (the anthropic faction or restoration interventions, through manipulation, transport or improper storage or through vandalism, explosions, fires, and floods (accidental or willful), can lead the artefact to the state of precollapse or collapse (end of use life - Sandu 2008).

The natural resistance of wood to exogenous factors and agents depends on the species, age of the tree, origin (area of harvest), time of felling, period and manner of processing and preservation, as well as the quantity and type of the active natural principle against insects and fungi or of the one introduced by the preservation treatments (Bhat et al. 2005, Luta et al. 2006, Thulasidas \& Bhat 2007, Sandu 2008, Sandu et al. 2010, Dungani et al. 2012, Sandu et al. 2015). As such, teak wood has a high commercial value, as it meets the requirements for its use as a wood with superior natural durability, which does not require preservation interventions (Dungani et al. 2012).

It is known that the wooden species that have low natural durability require preservation treatments when turned into final 
products or later during their use life, in order to improve their performance as materials and extend their lifespan. The most common treatment procedures employ depending on the species, the age of the tree, the age of the timber, the structuralornamental complexity, and the size and state of the artifact - various ecological systems for preservation based on active principles anti insects and fungi, in the form of solutions of aqueous or alcoholic microdispersions or of other organic solvents. The procedures used for applying them are immersion, brushing or spraying, as well as vacuum or pressure technologies, which provide high protection against insecto-fungic attacks (Bolin \& Smith 2011, Lebow 2010, Sandu 2008).

According to some authors (Lin et al. 2009, Feraydoni \& Hosseinihashemi 2012, Kartal et al. 2015), these active principles can include various chemical substances such as: arsenic salts, chrome salts, copper salts, zinc salts, and boron salts, which have the drawback of being expensive and toxic to the operator, owner and the environment. Moreover, these procedures required periodical re-treatments through time, which makes their use dangerous (Wang et al. 2016).

Currently, a wide range of synthetic (Luta et al. 2006, Sandu et al. 2015) or natural (Vasilache et al. 2009) substances are used for this purpose, as aqueous or organic solutions, emulsions or nanodispersions, which on account of being applied on the surface (as protection films) or inside the wood require periodic treatments that are hard to carry out once the artefact has been executed.

Given these aspects and the insectofungic protective role played by a number of natural extractable compounds from various plants (including flowers and seeds) or trees (oak, acacia, chestnut, mimosa, and teak), their investigation has become a very active area of research. Indeed, there is a large number of studies on the use of substances extracted from wooden species with high natural durability, as eco-friendly preservation agents ( $\mathrm{Na}$ kayama et al. 2001, Mburu et al. 2007, Syofuna et al. 2012, Kirker et al. 2013, Tascioglu et al. 2013, Mohammed et al. 2016).

Many studies on teak wood are present in the literature, though most are focused on the base wood components (lignin, cellulose and hemicellulose - Hisamochi et al. 2018). Few authors were concerned with the study of the nature and composition of the extracts from wooden species that are very resistant to insect or fungal attack ( Da Silva Leonardo et al. 2015, Brocco et al. 2017). In regards to teak wood, the antimicrobial effect of extracts is well known (Lacret et al. 2012, Niamke et al. 2012, Aboaba et al. 2014, Kopa et al. 2014, Paes et al. 2015, Brocco et al. 2017). Another study very close to the present one (Qiu et al. 2019) shows that extracts of teak wood in acetone contains 49 compounds with in- secto-fungic activity, of which the most representative are: 4-tert-butil-2-fenil-fenol, 2-metilantraquinone, and 2,3-dimetil-1,4,4a, 9a-tetrahidro-9,10-antracenedione.

The specialized literature on treatments for preserving old processed wood using active principles extracted from teak is limited to hot water and ethyl alcohol extracts, without presenting the chemical composition of the components (Aboaba et al. 2014). In some studies the low natural durability of teak grown in plantation from Panama were investigated (Haupt et al. 2003). In other studies, the heartwood extractive chemical components of teak from different provenances was studied by GCMS analysis (Xie et al. 2011). Moreover, the effect of some heartwood extractives was studied in order to highlight the impact on symbiotic protozoan communities and termite species (Babar et al. 2017)

This paper assesses the capacity to obtain the active principles of the teak wood in extraction processes using various solvents, determining the rate of extraction and the nature of the main components with various potential. Moreover, the purpose is the optimisation of the extraction conditions by using different organic solvents, alone or in mixture, in order to determine the efficacy of the extraction processes (quantity and number of extracted compounds). The experimental data highlighted the difference from the nature of the extracted compounds and their quantity for each studied extraction system.

\section{Materials and methods}

We used thin teak wood veneer (Tectona grandis L.f.) with no anatomical defects (knots, gnarls, torsades, etc.), with an age of 40 years. The samples were provided by a furniture factory in Iasi, Romania and imported from Thailand. Teak wood veener weighing $400 \mathrm{~g}$ were dried and mechanically divided by chopping, and subsequently ground in a ceramic ball mill, in order to obtain particles below $0.1 \mathrm{~mm}$. For each sample $10 \mathrm{~g}$ were weighted, and the powder was dispersed into a series of preset solvents, from which the active components were extracted in the form of organic mixture. Organic solvents of the p.f.a. (pure for analysis) group were used for extraction, specifically: ethylic alcohol (96\%), isopropyl alcohol (99.7\%), acetone (99\%), and acetone-isopropanol (60:40 ratio) co-solvent mixture.

The experiment consisted in 12 Erlenmeyer screw-cap flasks with each of the three solvents and the acetone-isopropanol mixture. In each flask $50.0 \mathrm{~mL}$ of solvent was added to $10 \mathrm{~g}$ of teak powder. The flask was shaken every hour for $60 \mathrm{sec}$, for a period of $10 \mathrm{~h}$. The dispersion was subsequently decanted for $14 \mathrm{~h}$ and then filtered with a Büchner funnel. One $\mathrm{mL}$ of filtrate was taken and its solvent evaporated on a watch glass that was weighted beforehand $\left(m_{g}\right)$. The watch glass and the filtrate were weighted $\left(m_{\mathrm{g}+\mathrm{f}}\right)$, and after the evaporation of the solvent (normal conditions for 24-72 h, depending on solvent) the watch glass with the extract was weighted $\left(m_{\mathrm{g}+\mathrm{e}}\right)$. The concentration of the organic extract was determined according to the relation (ASTM International 2001 eqn. 1):

$$
c(\%)=100 \cdot \frac{m_{g+e}-m_{g}}{m_{g+f}-m_{g}}
$$

For each solvent the evaluation was done as the arithmetic average of the three values obtained by evaporation.

The extract samples were analyzed by means of scanning electron microscopy, coupled with X-ray diffraction (SEM-EDX) and liquid chromatography, coupled with mass spectrometry (GC+MS).

The scanning electron microscopy produced microphotographs showing the morphology of the longitudinal and radial sections of the teak wood used for obtaining the powder and the extracts, and the EDX spectra provided the elemental composition in mass percentages of the main chemical components. For this purpose we used a scanning electron microscope (SEM), model VEGA II LSH (Tescan, Czech Republic), coupled with an EDX detector model Quantax QX2 (Bruker/Roentec, Germany). The analysis of the samples was performed at a magnification of $200 \times$ to $2500 \times$, with an acceleration tension of 30 $\mathrm{kV}$, and a work pressure lower than $1 \times 10^{-2}$ $\mathrm{Pa}$. The SEM image was acquisitioned using secondary (SE) and backscattered electrons (BSE).

The analysis of the chemical derivatives in the extracts was performed by GC (Gas Chromatography) technique (model 6890 $\mathrm{N}$, (Agilent Technologies Inc., CA, USA) in conjunction with an Agilent 5975 mass spectrometer (Sandu et al. 2003). The chromatographic conditions were differentiated according to the devices involved in the chromatography, as follows: the oven with a temperature $50^{\circ} \mathrm{C}$ at the onset, then raised at a rate of $15^{\circ} \mathrm{C}$ per minute firstly to $150{ }^{\circ} \mathrm{C}$ and then to $320{ }^{\circ} \mathrm{C}$, which was retained for $15 \mathrm{~min}$; the HP-5MS column, measuring $30 \mathrm{~mm} \times 0.25 \mathrm{~mm} \times 0.25 \mu \mathrm{m}$, with flow rate of $1.0 \mathrm{~mL} \mathrm{~min}^{-1}$; the sample injection was splitless (the entire sample) at a temperature of $270^{\circ} \mathrm{C}$. The mass spectrometry conditions were an El (electronic ionization) source with an electron bombardment energy of $70 \mathrm{eV}$, an ion source temperature of $230{ }^{\circ} \mathrm{C}$, and transfer line temperature of $280{ }^{\circ} \mathrm{C}$. The compounds were identified by comparing the MS (mass spectrometry) spectra to the National Institute of Standards and Technology library (NIST 2018) with retention time and indexes.

In this experiment, for the three components of the GC technique, the following parameters were used: (i) oven, which started from an initial temperature of $50{ }^{\circ} \mathrm{C}$ and reached a maximum temperature of $320^{\circ} \mathrm{C}$ in $44.92 \mathrm{~min}$; (ii) syringe for the splitless injection of sample (the entire sample 
is injected once, in order to obtain a higher concentration and a better selection of the component substances) at an initial temperature of $270{ }^{\circ} \mathrm{C}$, a pressure of $7.12 \mathrm{psi}$, with the flow rate varying for 2 min from 20.0 to $24.1 \mathrm{~mL} \mathrm{~min}^{-1}$; (iii) column - product separation was achieved by using the carrier gas helium with a flow rate of $1 \mathrm{~mL}$ $\mathrm{min}^{-1}$.

Detection was achieved using an acquisitioning system, with the information processed according to an S975 Agilent database, in scan mode, with the mass unit from 30.0 to 550.0 .

\section{Results and discussion}

To identify the main organic derivatives from teak wood that account for its great resistance to insect and fungal attack, we initially resorted to a wide range of solvents. After a series of preliminary tests on their extraction efficiency, only three solvent were selected (ethanol, isopropanol and acetone), along with the acetone-isopropanol mixture, which were used in the selective extraction of the organic compounds with insecto-fungicidal activity from teak wood.

Tab. 1 shows that the acetone-isopropanol mix has the greatest extraction yield, followed by acetone, ethyl alcohol and isopropanol, respectively. This result was expected, as the available literature shows that acetone extracts better than ethyl alcohol (Deng 2006), and among alcohols, isopropanol is miscible in water and nonpolar solvents, without evaporation traces left behind, making it the most recommended solvent for extraction protocols (Burlage 1947, Reeve et al. 1979, Yaws 1999, Green \& Wittcoff 2003).

SEM-EDX analysis was first conducted on the two sections - radial and longitudinal of the teak wood from which the powder was obtained, in structurally representative areas, for which the SEM microphotographs were made and incorporated into the EDX spectra (Fig. 1a, Fig. 1b). We continued with the analysis of the films of evaporated extract from the four organic solutions (Fig. 1C-f). The SEM-EDX analysis allowed assessing the texture, morphology and distribution of the anatomo-structural components of the wood fibers in the two sections, alongside the uniformity and morphology of the mixture of products from the evaporated extracts. On the basis of the EDX spectra, Tab. 2 presents the elemental composition of the teak wood in the two sections and for the four organic extracts.

We notice that in the radial section the microphotograph allowed a detailed rendering of the anatomo-structural components, with the parallel orientation of the fibers and of the resinophoric or gumiphoric channels, alongside the parenchymatous reserve cells with thickened and lignified walls, whereas in the longitudinal section only oriented arrangements of cellulose fibers and their defects were visible.
Conversely, the films of organic compounds obtained by evaporating the extracts appear as shinny resins, weakly colored in yellowish-brown, with a uniform arrangement of certain components that solidified differently when the solvent evapocroalveoli, some of which were ruptured.

Tab. 2 shows that the elemental composition in gravimetric percentages (\%) differs in the two sections for all the elements identified, except for magnesium, which has approximately equal concentrations, and for chlorine, which is present in both sections of the wood sample. In the two sections $(R)$ and $(L)$ there is an inversion of carbon and oxygen, specifically about twotimes diminishing of silicon and four times diminishing of aluminum, and again an inversion of calcium of about two times. This can be explained by the different distriburated, in the form of glomerules and mi-

Tab. 1 - Concentration of extracts from teak wood in the selected solvents.

\begin{tabular}{clc}
\hline $\begin{array}{c}\text { Sample } \\
\text { no. }\end{array}$ & Solvent & $\begin{array}{c}\text { Conc. } \\
\text { (\%) }\end{array}$ \\
\hline S1 & Isopropanol & 0.4435 \\
\hline S2 & Ethyl alcohol & 0.8888 \\
\hline S3 & Acetone & 0.9393 \\
\hline S4 & $\begin{array}{l}\text { Volumetric mixture } \\
\text { of acetone 60\% and } \\
\text { isopropanol 40\% }\end{array}$ & 0.9634 \\
\hline
\end{tabular}

tion along the analyzed surface of the chemical compounds.

The four organic extracts were analyzed by GC-MS (Figs. 2-5), showing that among the large series of compounds present in the teak wood in the form of resins, sug-
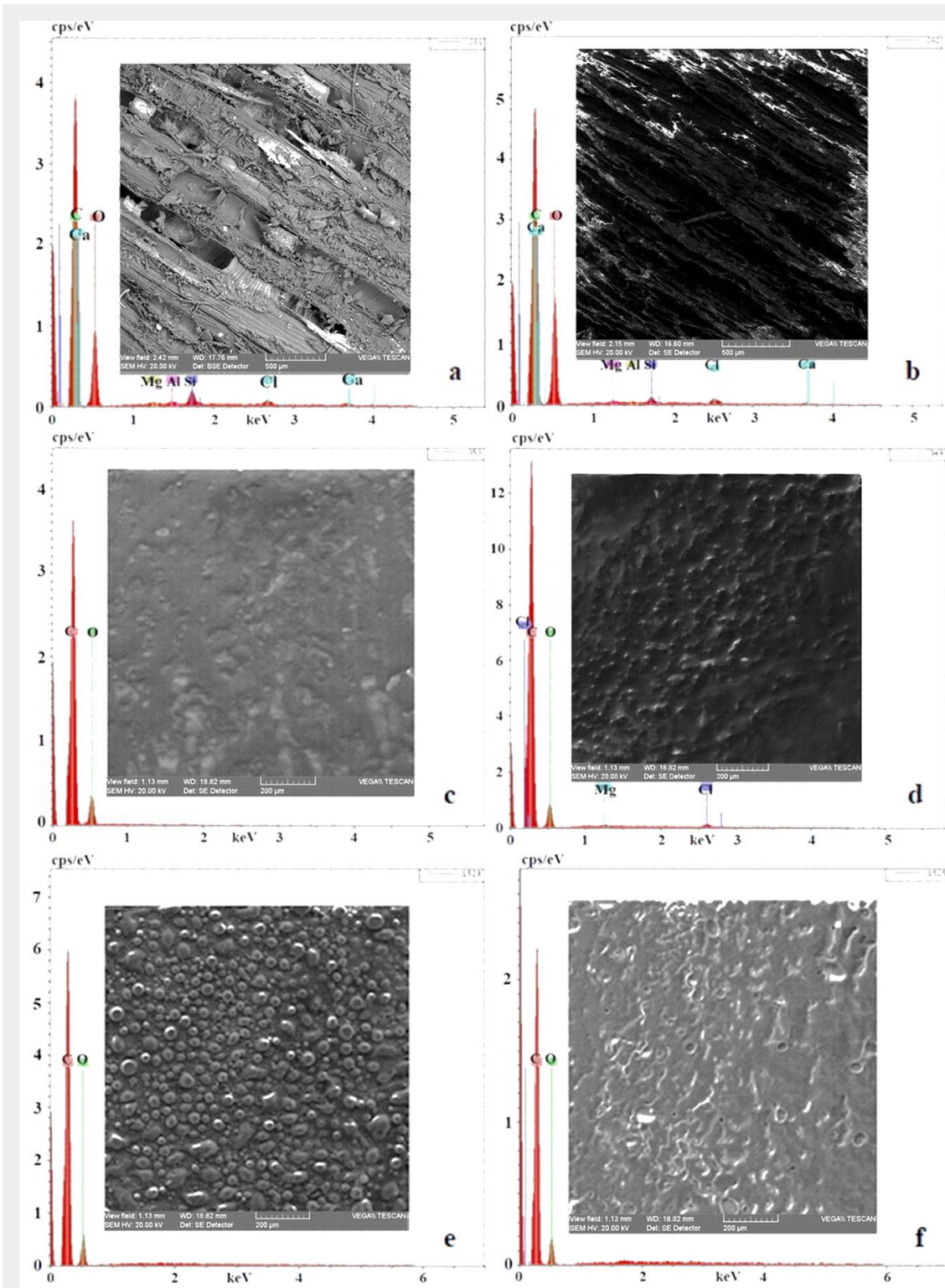

Fig. 1 - SEM images for the sample under analysis. (a): teak wood - radial section; (b): teak wood - longitudinal section; (c): extract in isopropyl alcohol; (d): extract in ethyl alcohol; (e): extract in acetone; (f): extract in a mixture of $60 \%$ acetone and $40 \%$ isopropyl alcohol. 
Tab. 2 - The elemental composition in gravimetric percentages (\%) for analysis samples.

\begin{tabular}{lllllllllc}
\hline \multirow{2}{*}{ Sample } & \multicolumn{7}{l}{ Elemental composition, gravimetric percentages (\%) } \\
\cline { 2 - 10 } & $\mathrm{C}$ & $\mathbf{0}$ & $\mathrm{Si}$ & $\mathrm{Al}$ & $\mathrm{Ca}$ & $\mathrm{Mg}$ & $\mathrm{Na}$ & $\mathrm{Cl}$ \\
\hline Teak R & 49.6864 & 48.0086 & 1.2227 & 0.2451 & 0.3992 & 0.2657 & - & 0.1723 \\
\hline Teak L & 45.3642 & 52.8382 & 0.6158 & 0.0636 & 0.6391 & 0.2686 & - & 0.2105 \\
\hline S1 & 63.9852 & 36.0148 & - & - & - & - & - & - \\
\hline S2 & 64.3797 & 34.8584 & - & - & - & - & - & 0.7620 \\
\hline S3 & 65.0967 & 34.9033 & - & - & - & - & - & - \\
S4 & 66.0332 & 33.9668 & - & - & - & - & - & - \\
\hline
\end{tabular}

Tab. 3 - Organic derivatives identified by GC-MS, extracted in acetone.

\begin{tabular}{|c|ccc|}
\hline No. & Organic derivative & Minute & Spectrum \\
\hline 1 & Phthalic anhydride- & 7.761 & Fig. 2a \\
\hline 2 & $\begin{array}{l}\text { 1H-Cycloprop[e]azulene, decahydro-1,1,7-trimethyl-4- } \\
\text { methylene-, [1aR-(1a.alpha.,4a.beta.,7alpha.,7a)] }\end{array}$ & 8.776 & Fig. 2b \\
\hline 3 & $\begin{array}{l}\text { Naphthalene, 1,2,4a,5,6,8a-hexahydro-4,7-dimethyl-1- } \\
\text { (methylethyl)- }\end{array}$ & 8.900 & Fig. 2c \\
\hline 4 & $\begin{array}{l}\text { Naphthalene, 1,2,4a,5,6,8a-hexahydro-4,7-dimethyl-1- } \\
\text { (methylethyl)-, (1.alpha.,4a.alpha.,8a.alpha) }\end{array}$ & 9.102 & Fig. 2d \\
\hline 5 & .alpha.-Calacorene & 9.518 & Fig. 2e \\
\hline 6 & .alpha.-Cadinol & 10.669 & Fig. 2f \\
\hline 7 & 9,10-Anthracenedione, 2-methyl- & 15.708 & Fig. 2g \\
\hline 8 & 2-(Hydroxymethyl)anthraquinone- & 19.769 & Fig. 2h \\
\hline & & & \\
\hline
\end{tabular}

ars/polysaccharides, fatty acids, esters, number of derivatives, but acetone and the phenols, terpenes, oils, and tannins had a acetone-isopropyl alcohol mix had the greater capacity of selective extraction. highest efficiency.

Ethyl alcohol and acetone extracted a large The number of organic derivatives identi- fied by GC-MS in the extracts obtained using the four solvent systems decrease as follows: acetone (8 derivatives), ethyl alcohol (8 derivatives), acetone-isopropanol mix (4 derivatives), and isopropanol ( 2 derivative); this was unexpected, given that the last is considered a solvent with a very high emollience and washing power for foulants, and which does not leave evaporation traces, but which increased the efficiency of the extraction in the mixture with acetone.

Of the eight derivatives extracted in acetone (Tab. 3, Fig. 2), four are also found in the ethyl alcohol extract (Tab. 4, Fig. 3), four in the acetone and isopropyl alcohol mix (Tab. 5. Fig. 4), which had the highest extraction efficiency and a single organic derivative, namely 9,10-Anthracenedione, 2-methyl- (Fig. 5) extracted in isopropanol, which can be found in all the extracts.

Tab. 3 presents the organic derivatives extracted from the teak wood in acetone, identified by GC-MS, according to the mass spectra from Fig. 2.

Tab. 4 presents the eight organic compounds from teak wood extracted in ethyl alcohol, identified according to the mass spectrum displayed in Fig. 3. Four of the compounds were also found in acetone (Phthalic anhydride, 2H-Naptho [2,3-b]pyran-5.10-dione, 2,2-dimethyl-, 9,10-Anthracenedione, 2-methyl- and 2-(Hydroxymeth$\mathrm{yl}$ )anthraquinone-), but at somewhat lower minutes: 7.761, 14.812, 15.708, 19.769.

Tab. 5 presents the organic derivatives extracted from the teak wood in the acetone-isopropyl alcohol mixture (6/4 vol.),
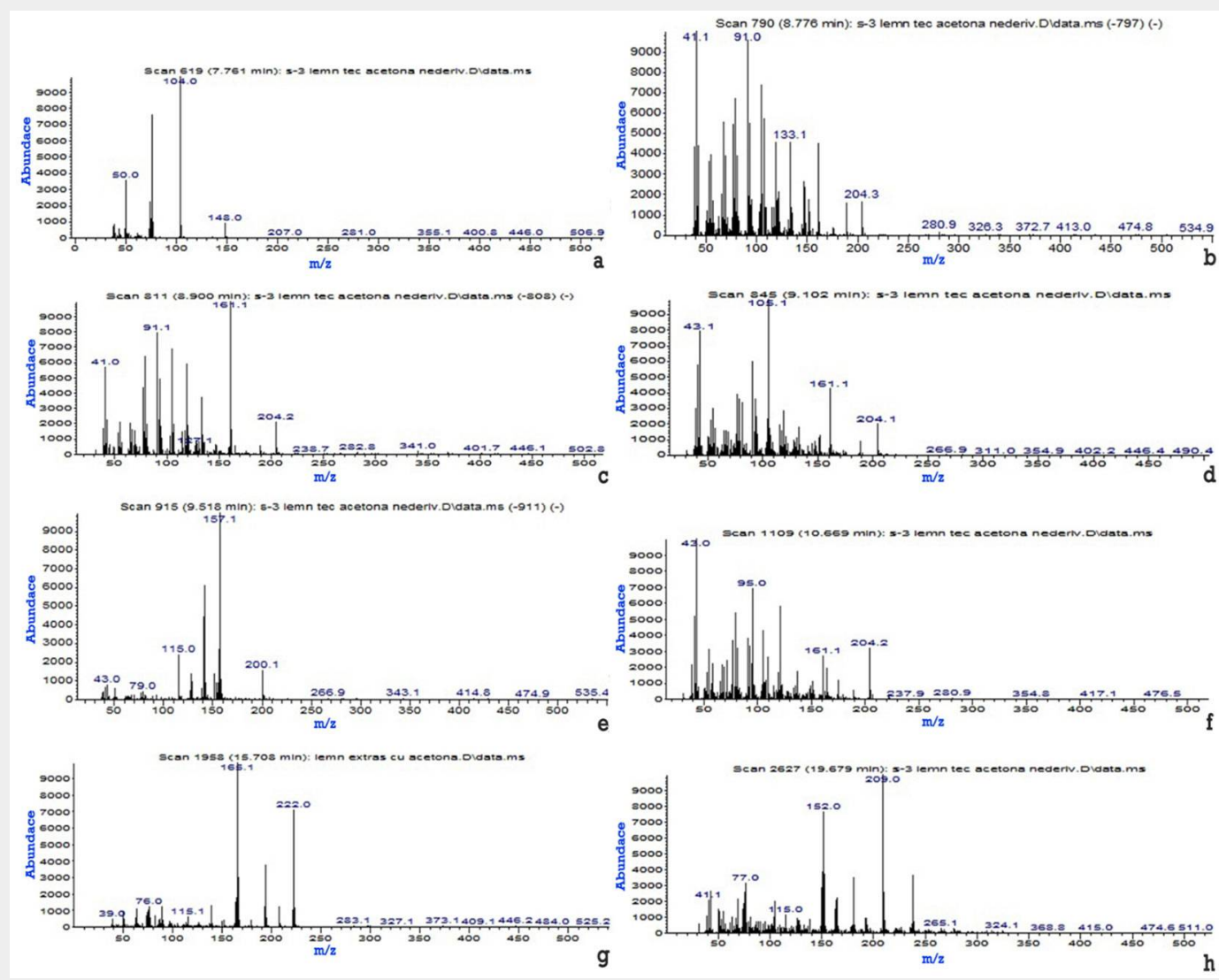

Fig. 2 - Mass spectra of the eight organic derivatives identified in the teak wood extract in acetone. (a): Phthalic anhydride; (b): $1 \mathrm{H}$-Cycloprop[e]azulene, decahydro1,1,7-trimethyl-4-methylene-, [1aR-(1a.alpha., 4a.beta.,7alpha.,7a)]; (c): Naphthalene, 1,2,4a,5,6, 8a-hexahydro-4,7-dimethyl-1-(methylethyl)-; (d): Naphthalene, 1,2,4a,5,6,8a-hexahydro4,7-dimethyl-1-(methylethyl)-(1.alpha.,4a.alpha., 8a.alpha); (e): .alpha.Calacorene; (f): .alpha.Cadinol; (g): 9,10Anthracenedione, 2methyl-; (h): 2-(Hydroxymethyl)anthraquinone. 
identified by GC-MS, according to the mass spectra from Fig. 4.

Fig. 5 presents the two derivatives, $2 \mathrm{H}$ Naphtho [2,3-b]pyran-5,10-dione, 2,2-dimethyl- and 9,10-Anthracenedione, 2-methyl-, extracted in isopropyl alcohol, identified from the mass spectrum at minutes 14.812 and 18.094 , respectively, which were also found in the ethyl alcohol extract, but at different minutes (17.176 and 18.175).

Of the eight derivatives extracted in acetone, identified according to the mass spectra, four were found in the ethyl alcohol extract (Phthalic anhydride $-2 \mathrm{H}-\mathrm{Naph}$ tho [2,3-b]pyran-5,10-dione, 2,2-methyl-, 9, 10-Anthracenedione, 2-methyl- and 2-(Hydroxymethyl)anthraquinone-), but at much higher minutes $(9.208,17.176,18.175$ and 21.740). Only four derivatives (Naphthalene, 1,2,4a,5,6,8a-hexahydro-4,7-dimethyl1-(methylethyl)-(1.alpha.,4a.alpha.,8a.alpha)-, alpha.-Cadinol-, 9.10-Anthracenedione, 2-methyl- and 9,10-Anthracenedione, 1-methyl-) were extracted in the acetoneisopropyl alcohol mixture, three of which were also found in the acetone extract (Naphthalene,1,2,4a,5,6,8a-hexahydro-4,7dimethyl-1-(methylethyl)-(1.alpha,4a.alpha, 8a.alpha); .alpha.-Cadinol- and 9.10-Anthracenedione, 2-methyl-), at approximately equal times, and only one (9,10-Anthracenedione, 1-methyl-) in the ethyl alcohol extract, but at minutes higher than 17.981.

The acetone-isopropyl alcohol mixture extracts fewer derivatives than acetone alone. By adding isopropanol a higher efficiency for extracting the four derivatives is provided.

We must underline that with the exception of isopropanol alone, acetone extracts selectively three derivatives $(1 \mathrm{H}$-Cycloprop-

Tab. 4 - Organic derivatives from teak wood identified by GC-MS, extracted in ethyl alcohol.

\begin{tabular}{|rlrc|}
\hline No. & Organic derivative & Minute & Spectrum \\
\hline 1 & Phthalic anhydride & 9.208 & Fig. 3a \\
\hline 2 & Vanillin & 10.034 & Fig. 3b \\
\hline 3 & 2H-Naphtho [2,3-b]pyran-5,10-dione, 2,2-methyl- & 17.176 & Fig. 3c \\
\hline 4 & [1,1'-Biphenyl]-2-ol, 5-(1,1-dimethylethyl)- & 17.331 & Fig. 3d \\
\hline 5 & $9,10-$ Anthracenedione, 1-methyl - & 17.981 & Fig. 3e \\
\hline 6 & 9,10 -Anthracenedione, 2-methyl- & 18.175 & Fig. 3f \\
\hline 7 & 2-(Hydroxymethyl)anthraquinone- & 21.740 & Fig. 3g \\
\hline 8 & Butyl(2-chlorocyclohexyl) methyl phthalate & 28.817 & Fig. 3h \\
\hline
\end{tabular}

Tab. 5 - Organic derivatives identified by GC-MS, extracted in the acetone-isopropyl alcohol mixture.

\begin{tabular}{rlrc}
\hline No. & Organic derivative & Minute & Spectrum \\
\hline 1 & $\begin{array}{l}\text { Naphthalene, 1,2,4a,5,6,8a-hexahydro-4,7-dimethyl-1- } \\
\text { (methylethyl)-, (1.alpha.,4a.alpha.,8a.alpha)- }\end{array}$ & 9.144 & Fig. 4a \\
\hline 2 & .alpha.-Cadinol- & 10.757 & Fig. 4b \\
\hline 3 & $9,10-$ Anthracenedione, 2-methyl- & 15.601 & Fig. 4c \\
\hline 4 & $9,10-$ Anthracenedione, 1-methyl- & 15.768 & Fig. 4d \\
\hline
\end{tabular}

[e]azulene, decahydro-1.1.7-trimethyl-4-methylene-, [1aR-(1a.alpha.,4a.beta.,7alpha., 7a)], Naphthalene, 1,2,4a,5,6,8a-hexahydro4,7-dimethyl-1-(methylethyl)- and alpha-Calacorene), and ethyl alcohol two (Butyl(2chlorocyclohexyl) methyl phthalate and [1,1'-Biphenyl]-2-ol, 5-(1,1-dimethylethyl)-), which are not found in other extracts, but which have a good insecto-fungicidal activity (Luta et al. 2006).

Among the derivatives extracted using the four selected organic solvent systems, most have good insecto-fungicidal activity, with the most active being the anthraquinones (9,10-Anthracenedione, 1-methyl-; 9,10-Anthracenedione, 1-methyl-; 2-(Hydroxymethyl)anthraquinone-; 2-Methyl-anthraquinone), naphthalenes (Naphthalene, 1,2, 4a,5,6,8a-hexahydro-4.7-dimethyl-1-(methyl ethyl)-(1.alpha.,4a.alpha.,8a.alpha); $\quad 2 \mathrm{H}-$ Naphtho [2,3-b]pyran-5,10-dione,2,2-dimethyl-), bisphenols ([1,1'-Biphenyl]-2-ol, 5-(1,1dimethylethyl)-), and the chlorine derivative (Butyl(2-chlorocyclohexyl) methyl ph-
Fig. 3 - Mass spectra of the eight organic derivatives identified in the teak wood extract in ethyl alcohol. (a) Phthalic anhydride; (b): Vanillin; (c): 2H-Naphtho [2.3-b]pyran-5.10-dione, 2.2 methyl-; (d): [1.1'-Biphenyl]2-ol, 5-(1.1-dimethylethyl)-; (e): 9.10-Anthracenedione, 1-methyl-; (f): 9.10Anthracenedione, 2methyl-; (g): 2-(Hydroxymethyl)anthraquinone-; (h): Butyl(2-chlorocyclohexyl) methyl phthalate.
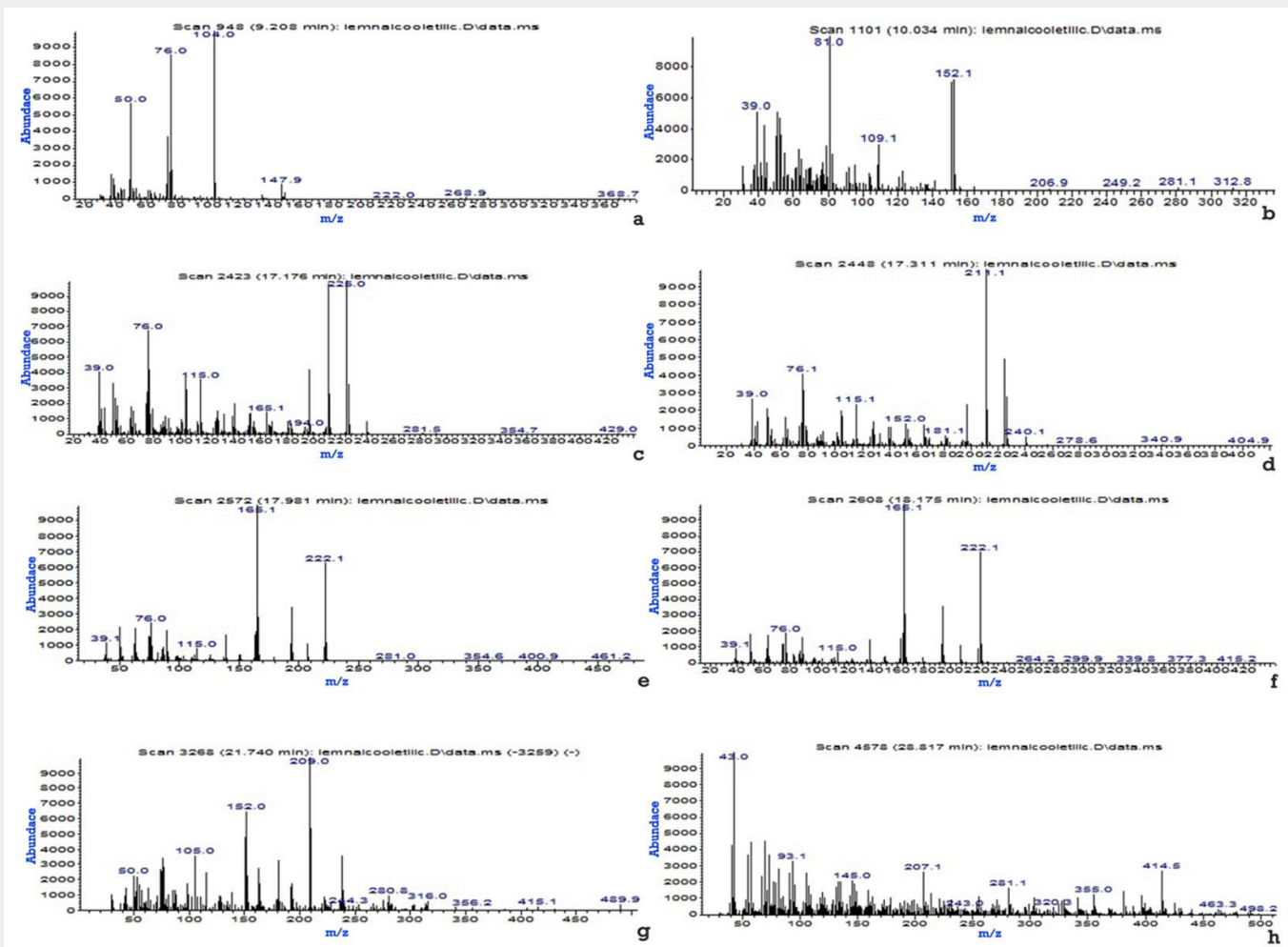
Fig. 4 - The mass spectra of the four organic derivatives identified in the teak wood extract in the acetone-isopropyl alcohol mixture (6/4 vol.). (a): Naphthalene, 1,2, 4a,5,6,8a-hexahydro-4,7-dimethyl-1(methylethyl)-(1.al pha.,4a.alpha., 8a.alpha)

(b): .alpha.-Cadinol; (c): 9,10-Anthracenedione, 2methyl-; (d): 9,10Anthracenedione, 1-methyl-.
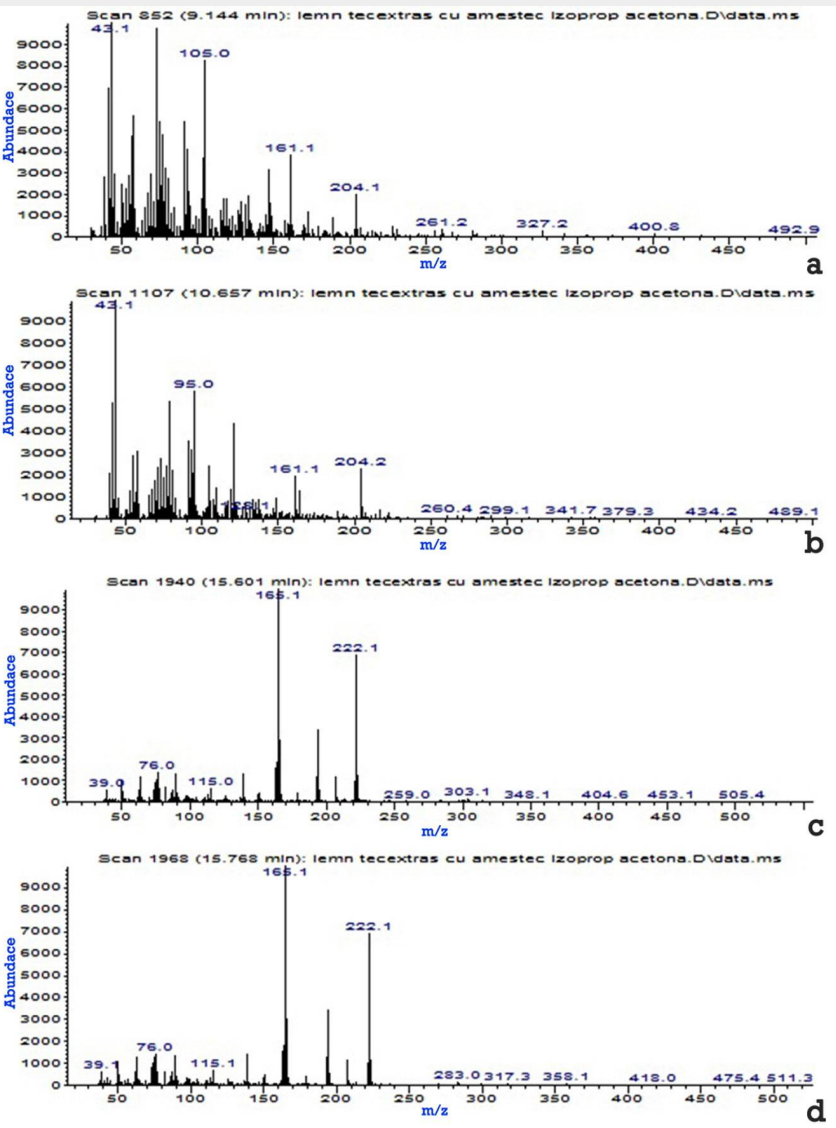

thalate/or butyl phthalate (2-clorociclohexil) methylic). Noteworthy, the only halogenated derivative of the series extracted from the teak wood, Butyl(2-chlorocyclohexyl) methyl phthalate, is found only in ethyl alcohol and was highlighted in the EDX spectra (Luta et al. 2006).

\section{Conclusions}

The results obtained by two instrumental techniques (SEM-EDX and GC + MS) in order to identify the organic compounds with insect-fungicidal activity present in teak wood (Tectona grandis), separated by extraction with organic solvents, the fol- lowing conclusions can be drawn:

- teak wood is part of the group of exotic species that are very resistant to biotic attacks, containing a large number of bioactive principles with insect-fungal activity, which so far are not sufficiently known;

- for their extraction from fine powder of old teak wood from 40-year-old trees, a working protocol was elaborated on the basis of preliminary experiments using a large number of organic solvents, which allowed to select the following four systems: isopropyl alcohol, ethyl alcohol, acetone and a mixture of acetone and isopropyl alcohol, with extraction capac-
Fig. 5 - Mass spec tra of the organic derivatives identified in the teak wood extract in isopropyl alcohol. (a): $2 \mathrm{H}$-Naphtho [2,3-b]pyran-5,10dione, 2,2-dimethyl-; (b): 9,10-Anthracenedione, 2methyl-.
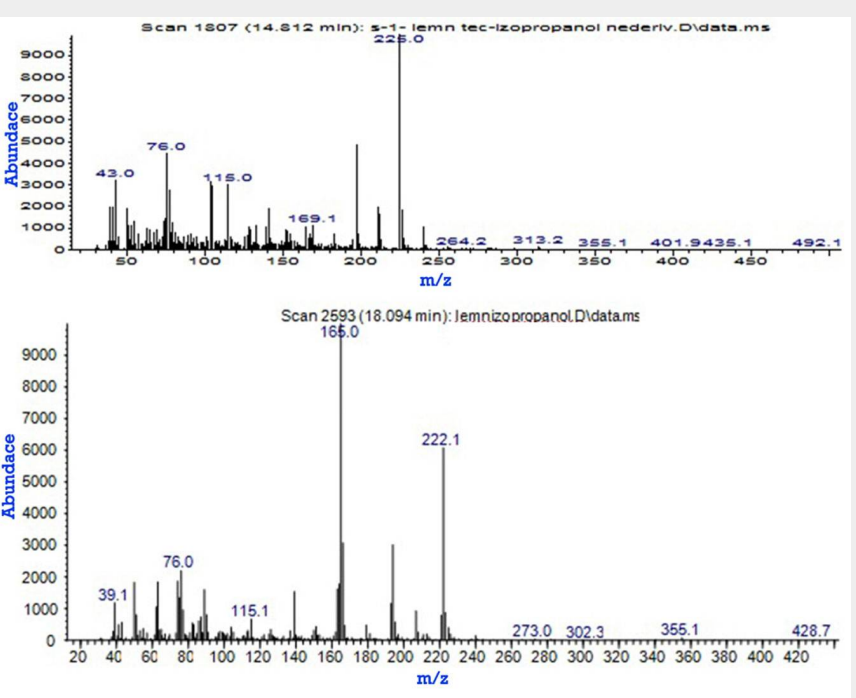

ity increasing in the above order;

- each extraction system presented a different selectivity for separating the bioactive principles, as follows: the extract in acetone separated eight organic compounds, the one in ethyl alcohol also eight, the acetone-isopropanol mixture four and only two in isopropanol;

- of the four extraction systems, the most efficient was acetone and the acetoneisopropyl mixture;

- of the eight organic compounds identified in the acetone extract, three are among the eight extracted in ethyl alcohol and four in the acetone-isopropyl alcohol mixture;

- of the two organic compounds identified in isopropyl alcohol, the first ( $2 \mathrm{H}-\mathrm{Naphtho}$ [2,3-b] pyran-5,10-dione, 2,2-dimethyl-) is also found in the ethyl alcohol extract, and the second (9,10-anthracendion, 2methyl-) is found in all four extracts;

- acetone selectively extracts three derivatives that are not found in other extracts (1H-Cycloprop[e]azulene, decahydro-1,1,7trimethyl-4-methylene-, [1aR- (1a.alpha., 4a.beta.,7alpha.,7a)], naphthalene, 1,2,4a, 5,6,8a-hexahydro-4,7-dimethyl-1- (methylethyl)- and .alpha-(alacoren), and ethyl alcohol two (butyl (2-chlorocyclohexyl)) phthalate methyl and [1,1'-biphenyl] -2-ol, 5(1.1-dimethylethyl)-);

- of the compounds extracted using the four selected organic solvent systems, the most active are: anthraquinones ( 9 , 10-Anthracenedione, 1-methyl-; 9,10-Anthracenedione, 1-methyl-; 2- (Hydroxymethyl) anthraquinone; 2-Methyl-anthraquinone), naphthalenes (naphthalene, 1 , 2,4a,5,6,8a-hexahydro-4.7-dimethyl-1-(methylethyl)) - (1.alpha, 4a.alfa, 8a.alfa); $2 \mathrm{H}$ Naphtho [2,3-b] pyran-5,10-dione, 2,2dimethyl-), bisphenol ([1,1'-biphenyl] -2-ol, 5- (1,1-dimethylethyl)-) and the chlorinated derivative (butyl (2-chlorocyclohexyl) methyl phthalate), the latter being found only in ethyl alcohol;

- of the four extracts the most indicated to be used in the preservation treatments of old wooden artifacts, with active biotic attack, is the concentrated extract in ethyl alcohol, which has the lowest toxicity and which extracts the chlorinated compound, the most effective in the biocide treatments.

\section{References}

Aboaba S, Akande A, Flamini G (2014). Chemical constituents, toxicity and antimicrobial activities of the essential oil from the leaves of Tectona grandis. Elixir BioTechnology 75: 2738427387. [online] URL: http://arpi.unipi.it/handle/ 11568/274535\#.YNHcE-gza8E

ASTM International (2001). Standard test method for preparation of extractive-free wood. West Conshohocken, PA, USA. [online] URL: http://file.yizimg.com/175706/2011120520563359 .pdf

Babar H, Mankowski ME, Kirker G, Ahmed S (2017). Effects of heartwood extractives on symbiotic protozoan communities and mortal- 
ity in two termite species. International Biodeterioration and Biodegradation 123: 27-36. - doi: 10.1016/j.ibiod.2017.05.023

Bhat KM, Thulasidas PK, Florence EJM, Jayaraman K (2005). Wood durability of home-garden teak against brown-rot and white-rot fungi. Trees-Structure and Function 19: 654-660. - doi: 10.1007/s00468-005-0429-0

Bolin CA, Smith S (2011). Life cycle assessment of ACQ-treated lumber with comparison to wood plastic composite decking. Journal of Cleaner Production 19: 620-629. - doi: 10.1016/j.jclepro. 2010.12.004

Brocco VF, Paes JB, Da Costa LG, Brazolin S, Arantes MDC (2017). Potential of teak heartwood extracts as a natural wood preservative. Journal of Cleaner Production 142: 2093-2099. doi: 10.1016/j.jclepro.2016.11.074

Burlage HM (1947). Pharmaceutical applications of isopropyl alcohol II. Solubilities of local anesthetics. Journal of the American Pharmaceutical Association 36: 17-19. - doi: 10.1002/jps.30303 60105

Da Silva Leonardo FV, Rocha HF, Hurtado de Mendoza ZM (2015). Compostos químicos em teca [Chemical compounds in teak]. Pesquisa Florestal Brasileira 35 (83): 315. [in Portuguese] - doi: 10.4336/2015.pfb.35.83.816

Deng Z (2006). Development of an alternative solvent to replace benzene in the determination of organic soluble extractives in wood. World Pulp and Paper 25: 32-34. [online] URL: http://en.cnki.com.cn/Article_en/CJFDTotal-GJZ Z200603010.htm

Dungani R, Bhat IH, Abdul Khalil HPS, Naif A, Hermawan D (2012). Evaluation of antitermitic activity of different extracts obtained from Indonesian teakwood (Tectona grandis L.f). BioResources 7: 1452-1461. - doi: 10.15376/biores.7. 2.1452-1461

Feraydoni V, Hosseinihashemi SK (2012). Effect of walnut heartwood extractives, acid copper chromate, and boric acid on white-rot decay resistance of treated beech sapwood. BioResources 7: 2393-2402. - doi: 10.15376/biores.7.2. 2393-2402

Green MM, Wittcoff HA (2003). Organic chemistry principles and industrial practice. WileyVCH, Weinheim, Germany, pp. 341. [online] URL: http://sutlib2.sut.ac.th/sut_contents/H870 93.pdf

Haupt M, Leithoff H, Meier D, Puls J, Richter HG, Faix O (2003). Heartwood extractives and natural durability of plantation-grown teakwood (Tectona grandis L.) a case study. Holz als Rohund Werkstoff 61: 473-474. - doi: 10.1007/soo1 07-003-0428-z

Hayashi M, Sandu I, Tiano P, Macchioni N (2010). The effect of preservative interventions on the chemical-physical and structural characteristics of panel painting. "Al. I. Cuza” University Publishing House, lasi, Romania, pp. 130.

Hisamochi R, Watanabe Y, Sano M, Nakatsuka T, Kurita N, Matsuo-Ueda M, Yamamoto H, Tazuru S, Sugiyama J, Subiyanto B (2018). Cellulose oxygen isotopic composition of teak (Tectona grandis) collected from Java Island: a tool for dendrochronological and dendroclimatological analysis. Dendrochronologia 52: 80-86. - doi: 10.1016/j.dendro.2018.09.010

lurcovschi CT, Munteanu M, Amariei CM, Lu- pascu MM, Sandu ICA, Vasilache V, Sandu I (2017). The impact of the treatment with Campeni red petroleum on a XVIII-th century icon. Chemistry Journal of Moldova 12: 53-60. - doi: 10.19261/cjm.2017.406

Kartal SN, Terzi E, Yilmaz H, Goodell B (2015). Bioremediation and decay of wood treated with ACQ, micronized ACQ, nano-CuO and CCA wood preservatives. International Biodeterioration and Biodegradadation 99: 95-101. - doi: 10.1016/j.ibiod.2015.01.004

Kirker GT, Blodgett AB, Arango RA, Lebow PK, Clausen CA (2013). The role of extractives in naturally durable wood species. International Biodeterioration and Biodegradation 82: 53-58. doi: 10.1016/j.ibiod.2013.03.007

Kopa TK, Tchinda AT, Tala MF, Zofou D, Jumbam R, Wabo HK, Titanji VPK, Frederich M, Tan NH, Tane $P$ (2014). Antiplasmodial anthraquinones and hemisynthetic derivatives from the leaves of Tectona grandis (Verbenaceae). Phytochemistry Letters 8: 41-45. - doi: 10.1016/j.phytol.201 4.01.010

Lacret R, Varela RM, Molinillo JMG, Nogueiras C, Macias FA (2012). Tectonoelins, new norlignans from a bioactive extract of Tectona grandis. Phytochemistry Letters 5: 382-386. - doi: 10.101 6/j.phytol.2012.03.008

Lebow ST (2010). Wood preservation. Wood handbook-wood as an engineering material. General Technical Report FPL-GTR-190, USDA Forest Service, Forest Products Laboratory, Madison, WI, USA, pp. 1-28. [online] URL: http://www.fs.usda.gov/treesearch/pubs/all/37 417

Lin LD, Chen YF, Wang SY, Tsai MJ (2009). Leachability, metal corrosion, and termite resistance of wood treated with copper-based preservative. International Biodeterioration and Biodegradation 63: 533-538. - doi: 10.1016/j.ibiod.2008. 07.012

Luta N, Sandu I, Petreus O (2006). Produse si tehnologii pentru conservarea patrimoniului cultural si istoric [Products and technologies for the conservation of cultural and historical heritage]. Performantica, Iasi, Romania, pp. 286. [in Romanian]

Mburu F, Dumarçay S, Gérardin P (2007). Evidence of fungicidal and termicidal properties of Prunus africana heartwood extractives. Holzforschung 61: 323-325. - doi: 10.1515/HF.2007.043

Mohammed SA, Madhan B, Demissie BA, Velappan B, Tamil Selvi A (2016). Rumex abyssinicus (mekmeko) Ethiopian plant material for preservation of goat skins: approach for cleaner leather manufacture. Journal of Cleaner Production 133: 1043-1052. - doi: 10.1016/j.jclepro.20 16.06.043

Nakayama FS, Vinyard SH, Chow P, Bajwa DS, Youngquist JA, Muehl JH, Krzysik AM (2001). Guayule as a wood preservative. Industrial Crops and Products 14: 105-111. - doi: 10.1016/So 926-6690(00)00093-5

Niamke FB, Amusant N, Stien D, Chaix G, Lozano $\mathrm{Y}$, Kadio AA, Lemenager N, Goh D, Adima AA, Kati-Coulibaly S, Jay-Allemand C (2012). 4',5'-Dihydroxy-epiisocatalponol, a new naphthoquinone from Tectona grandis L. f. heartwood, and fungicidal activity. International Biodeterioration and Biodegradation 74: 93-98. - doi: 10.101 6/j.ibiod.2012.03.010
NIST (2018). NIST standard reference database. SRD 69, NIST library, National Institute of Standards and Technology, US Secretary of Commerce, USA, web site. - doi: 10.18434/T4D303 Okanlawon FB, Olaoye KO (2020). Bio preservative potential of Ocimum basilicum L. leaf extract on Triplochiton scleroxylon (K. Schum) and Ceiba pentandra (L.) Gaertn. wood against termite attack. European Scientific Journal 16: 7681. - doi: 10.19044/esj.2020.v16n9p55

Paes JB, Brocco FV, Moulin JC, Motta JP, Alves $R C$ (2015). Efeitos dos extrativos e da densidade na resistencia natural de madeiras ao termita Nasutitermes corniger [Effect of extractives and density on natural resistance of woods to termite Nasutitermes corniger]. CERNE 21: 569-578. - doi: 10.1590/01047760201521041849 Qiu H, Liu R, Long R (2019). Analysis of chemical composition of extractives by acetone and the chromatic aberration of Teak (Tectona grandis L.f.) from China. Molecules 24: 1989. - doi: 10.3390/molecules24101989

Reeve W, Erikson CM, Aluotto PF (1979). A new method for the determination of the relative acidities of alcohols in alcoholic solutions. The nucleophilicities and competitive reactivities of alkoxides and phenoxides. Canadian Journal of Chemistry 57: 2747-2754. - doi: 10.1139/v79-444 Sandu I (2008). Degradarea si deteriorarea bunurilor de patrimoniu cultural [Degradation and deterioration of the cultural heritage]. "Al. I. Cuza” University Publishing House, lasi, Romania, vol. II, pp. 538. [in Romanian]

Sandu I, Vasilache V, Sandu ICA, Hayashi M (2010). A new method of determining the normal range of hydric-equilibrium variation in wood, with multiple applications. Revista de Chimie 61: 1212-1218. [online] URL: http://www. afir.org.ro/id423/files/RC1.pdf

Sandu ICA, Brebu M, Luca C, Sandu I, Vasile C (2003). Thermogravimetric study on the ageing of lime wood supports of old paintings. Polymer Degradation and Stability 80: 83-91. - doi: 10.1016/S0141-3910(02)00386-5

Sandu ICA, Hayashi M, Vasilache V, Cozma DG, Pruteanu S, Urma M, Sandu I (2015). Influence of organic solvents and dispersions on wooden supports of paintings. Revista de Chimie 66: 587-595. [online] URL: http://bch.ro/pdfRC/SAN DUIC.pdf415.pdf

Schultz TP, Nicholas DD (2002). Development of environmentally-benign wood preservatives based on the combination of organic biocides with antioxidants and metal chelators. Phytochemistry 61: 555-560. - doi: 10.1016/so031-9422 (02)00267-4

Spiridon P, Sandu ICA, Nica L, lurcovschi CT, Colbu DE, Negru IC, Vasilache V, Cristache RA, Sandu I (2017). Archaeometric and chemometric studies involved in the authentication of old heritage artefacts II. Old linden and poplar wood put into work. Revista de Chimie 68: 2422-2430. - doi: 10.37358/RC.17.10.5898

Syofuna A, Banana AY, Nakabonge G (2012). Efficiency of natural wood extractives as wood preservatives against termite attack. Maderas, Ciencia y Tecnologia 14: 155-163. - doi: $10.4067 /$ S0718-221X2012000200003

Tascioglu C, Yalcin M, Sen S, Akcay C (2013). Antifungal properties of some plant extracts used as wood preservatives. International Biodeteri- 
oration and Biodegradation 85: 23-28. - doi: 10.1016/j.ibiod.2013.06.004

Thulasidas PK, Bhat KM (2007). Chemical extractive compounds determining the brown-rot decay resistance of teak wood. Holz als Roh- und Werkstoff 65: 121-124. - doi: 10.1007/s00107-0060127-7

Vasilache V, Sandu I, Luca C, Sandu ICA (2009). Noutati în conservarea stiintfica a lemnului vechi policrom [News concerning scientific conservation of the old polychrome wood]. "Al. I. Cuza" University Publishing House, lasi, Romania, pp. 282. [in Romanian]
Walker JCF, Butterfield BG, Harris JM, Langrish TAG, Uprichard JM (1993). Primary wood processing. principles and practice. Chapman and Hall, London, UK, pp. 611.

Wang L, Chen SS, Tsang DCW, Poon CS, Shih K (2016). Recycling contaminated wood into ecofriendly particleboard using green cement and carbon dioxide curing. Journal of Cleaner Production 137: 861-870. - doi: 10.1016/J.JCLEPRO. 2016.07.180

Xie C, Li K, Lin J, Li J (2011). GC-MS analysis on heartwood extractive chemical components of different provenances of Teak (Tectona grandis
L.f.). Advanced Materials Research 236 (238): 1049-1053 - doi: 10.4028/www.scientific.net/AM R.236-238.1049

Yatagai $M$, Nishimoto $M$, Hori K, Ohira T, Shibata A (2002). Termiticidal activity of wood vinegar, its components and their homologues. Journal of Wood Science 48: 338-342. - doi: 10.1007/BF 00831357

Yaws CL (1999). Chemical properties handbook: physical, thermodynamics, environmental transport, safety and health related properties for organic and inorganic chemical. McGrawHill, New York, USA, pp. 784. 